\title{
Systemic chemotherapy with FOLFOX in metastatic grade 1/2 neuroendocrine cancer
}

\author{
MARJORIE FAURE ${ }^{1}$, PATRICIA NICCOLI ${ }^{1,2}$, AURELIE AUTRET ${ }^{3}$, \\ GERARD CAVAGLIONE $^{4}$, LAURENT MINEUR ${ }^{5}$ and JEAN-LUC RAOUL ${ }^{1}$ \\ ${ }^{1}$ Department of Medical Oncology, Paoli-Calmettes Institute, 13009 Marseille; \\ ${ }^{2}$ Department of Endocrinology and Medical Oncology, La Timone Hospital, Faculty of Medicine, \\ University of Mediterranée, 13005 Marseille; ${ }^{3}$ Biostatistics Department, Paoli-Calmettes Institute, \\ 13009 Marseille; ${ }^{4}$ Medical Oncology Department, Antoine Lacassagne Cancer Center, 06100 Nice; \\ ${ }^{5}$ Medical Oncology Department, Sainte-Catherine Institute, 84000 Avignon, France
}

Received June 13, 2016; Accepted October 7, 2016

DOI: $10.3892 / \mathrm{mco} .2016 .1097$

\begin{abstract}
Neuroendocrine tumors (NETs) comprise a heterogeneous group of malignancies with various clinical presentations and evolution. NETs are often diagnosed at a late stage, when they are already metastatic. Treatment is currently based on traditional chemotherapies, such as streptozocin, with serious side effects. The favorable toxicity profile of the combination of 5-fluorouracil with oxaliplatin, together with its significant antitumor activity in several gastrointestinal malignancies, led to the evaluation of its efficacy and tolerability in patients with advanced grade $1 / 2$ (G1/G2) NETs. The endpoints of the study were tumor response (according to the Response Evaluation Criteria in Solid Tumors 1.1), overall survival (OS), progression-free survival (PFS) and symptom improvement. From January, 2013 to January, 2015, during our Regional Multidisciplinary Tumor Board dedicated to NETs (RENATEN network), FOLFOX was recommended for the treatment of metastatic NETs as first-line therapy or after failure of other therapies. The inclusion criteria were metastatic, well-differentiated G1/G2 NETs, progressing within the last 3 months. Cases with previous antitumor therapy were allowed. The patients received modified FOLFOX-6 and were assessed every 3 months by computed tomography or magnetic resonance imaging examinations. A total of 31 patients were included. The median follow-up was 20 months [95\% confidence interval (CI): 15-27]. Nine patients (29\%) exhibited a partial response, and 13 (41\%) achieved stable disease; the disease control rate was $70 \%$. A total of 9 patients exhibited disease progression. The control rate was $78 \%$ for pancreatic and $65 \%$ for extra-
\end{abstract}

Correspondence to: Dr Marjorie Faure, Department of Medical Oncology, Paoli-Calmettes Institute, 232 Boulevard de Sainte Marguerite, 13009 Marseille, France

E-mail: marjorie_faure@hotmail.fr

Key words: chemotherapy, 5-fluorouracil, oxaliplatin, neuroendocrine tumors, response rate, survival, break in treatment, quality of life pancreatic NETs. The median OS was not reached; the 1- and 2 -year OS rates were 89 and $70 \%$, respectively (Fig. 1). No significant difference in OS was observed between the $<5$ and $5-20 \% \mathrm{Ki}-67$ subgroups $(\mathrm{P}=0.41)$ (Fig. $2 \mathrm{~A})$ or according to primary tumor location ( $\mathrm{P}=0.71)$ (Fig. $2 \mathrm{~B}$ ). The median PFS was 14.1 months (95\% CI: 9.3-24.1), with no significant difference in PFS between the Ki-67 subgroups $(\mathrm{P}=0.26)$ (Fig. 3A) or by primary tumor location $(\mathrm{P}=0.995)$ (Fig. $3 \mathrm{~B})$. The median time to treatment failure was 14.72 months $(95 \% \mathrm{CI}$ : $10.0-$ not estimable). No unusual toxicity or toxicity-related deaths were reported. Finally, 7 of 9 patients who achieved a partial response benefited from a break in treatment of $\geq 3$ months. The median duration of this break was 9.2 months (range, 3-42 months). Of the 13 patients with stable disease, 12 may have also benefited from a chemotherapy break. The median break duration was 10 months (range, 0.5-26 months).

\section{Introduction}

Neuroendocrine tumors (NETs) are a heterogeneous group of malignancies with various clinical presentations and evolution. NETs are often diagnosed at a late stage, when they are already metastatic (1). Their prognosis and treatment mainly depend on histological grade, which is based on the Ki-67 proliferation index (2). The recommended treatment for poorly differentiated grade 3 (G3; Ki-67>20\%) NETs is aggressive chemotherapy, usually based on cisplatin and etoposide. However, a proportion of G3 NETs are well-differentiated (3). The treatment of G1/G2 NETs has improved, but less so in cases with liver metastases (4-6) compared with disseminated disease, with the demonstration of the efficacy of somatostatin analogs $(7,8)$, targeted therapies (9-11), and, more recently, peptide receptor radionuclide therapy (PRRT) (12-14). After the demonstration of the efficacy of sunitinib and everolimus, these drugs may be considered as the first systemic line of treatment. Systemic chemotherapy remains a standard of care, as the results of the first randomized study demonstrated the efficacy of combining streptozocin (STZ) with either doxorubicin or 5-fluorouracil (5FU) (15). Later, a large phase II/III analysis (16) showed no difference between 5FU-doxorubicin 
and 5FU-STZ. Other combinations based on temozolomide have also been tested (17). Oxaliplatin, a platinum analog with a favorable safety profile, has significant activity against various gastrointestinal cancers (18-21); in addition, one case of response to an oxaliplatin-based regimen in a patient with metastatic carcinoid tumor has been reported (22). More recently, the results of a phase II trial of the combination of capecitabine and oxaliplatin in patients with advanced untreated NETs were reported (23). These well-tolerated chemotherapies have the advantage that, if the patient achieves partial response or stable disease, it may be possible to have a break from treatment (24) in order to improve safety and quality of life. The favorable toxicity profile of 5FU-oxaliplatin, together with its significant antitumor activity in several gastrointestinal malignancies, led to the evaluation of its efficacy and tolerability in patients with advanced G1/G2 NETs.

\section{Patients and methods}

Patient selection. From January, 2013 to January, 2015, during our Regional Multidisciplinary Tumor Board dedicated to NETs (RENATEN network), FOLFOX was proposed for the treatment of metastatic progressing NETs as first-line therapy or after failure of other therapies. The cases of patients treated in four centers of the RENATEN network in Provence (Paoli-Calmettes Institute, Marseille; La Timone Hospital, University of Mediterranée, Marseille; Antoine Lacassagne Cancer Center, Nice; and Sainte-Catherine Institute, Avignon) were retrospectively reviewed.

The inclusion criteria were as follows: NETs (in all cases, the diagnosis of neuroendocrine carcinoma was confirmed by an expert pathologist from the TEN-path network), progressing within the last 3 months, locally advanced or metastatic, well-differentiated and G1/G2. Previous treatments with chemotherapy, targeted therapies, transarterial chemoembolization, or somatostatin analogues were allowed. The exclusion criteria were as follows: G3 NET (Ki-67>20\%) or patients with other malignancies.

Treatment schedule. The patient files were retrospectively reviewed for efficacy outcomes [response rate and progression-free survival (PFS)], toxicities, clinical benefit and overall survival (OS). The patients received modified FOLFOX-6 (mFOLFOX; $85 \mathrm{mg} / \mathrm{m}^{2}$ oxaliplatin and $100 \mathrm{mg} / \mathrm{m}^{2}$ leucovorin as a $2-\mathrm{h}$ intravenous infusion on day 1 , followed by $5 \mathrm{FU}$ as a $400 \mathrm{mg} / \mathrm{m}^{2}$ bolus and then $2,400 \mathrm{mg} / \mathrm{m}^{2}$ as a $46-\mathrm{h}$ continuous infusion). The cycles were repeated every 2 weeks. Complete blood count, serum biochemistry and liver function tests were performed 24-48 h prior to each cycle. The chemotherapy doses were reduced if needed according to the standard guidelines. For oxaliplatin-specific toxicities (paresthesia and neuropathy), only the dose of oxaliplatin was reduced, first to $65 \mathrm{mg} / \mathrm{m}^{2}$ and then to $50 \mathrm{mg} / \mathrm{m}^{2}$.

Outcome evaluation. All the patients were assessed at the end of each cycle by clinical examination and blood tests, including chromogranin A (CgA) level, and every 3 months by $\mathrm{CT}$ scan and/or magnetic resonance imaging (MRI) and $\mathrm{CgA}$. The performance status and clinical symptoms (weight gain, pain and secretory symptoms) were recorded and a mean- ingful improvement in performance status and clinical signs was considered as a clinical benefit. Radiological response was classified according to the Response Evaluation Criteria in Solid Tumors, version 1.0 (http://jnci.oxfordjournals. org/content/92/3/205.long). A complete response was defined as disappearance of all target lesions, lasting for $\geq 4$ weeks. A partial response was defined as a decrease of $>30 \%$ in the sum of the largest perpendicular diameters of all measurable lesions, persisting for $\geq 4$ weeks, without progression of any non-measurable sites and without the appearance of new lesions. Progressive disease included an increase of $\geq 20 \%$ in the sum of the largest diameters of target lesions, taking as a reference the smallest largest diameter recorded since treatment initiation, or the appearance of $\geq 1$ new lesions. Stable disease was defined as neither sufficient shrinkage to qualify as a partial response nor sufficient increase to qualify as progressive disease. After chemotherapy withdrawal, the patients were followed up every 3 months with clinical and imaging examinations.

Statistical analysis. The statistical analysis was performed using SAS software, version 9.3 (SAS Institute, Cary, NC, USA). The baseline characteristics were summarized using descriptive statistics: Median and range for continuous variables, and number and percentage for categorical variables. OS was calculated from the date of chemotherapy initiation (cycle 1-day 1) to the date of death. PFS was calculated from the date of chemotherapy initiation (cycle 1-day 1) to the date of disease progression or death from any cause. The time-to-treatment failure (TTF) is defined as the duration between the first day of treatment and the development of toxicity or tumor progression, leading to the use of another therapeutic option. Patients without any event of interest were censored at the date of the last contact. Survival curves were estimated using the Kaplan-Meier method and compared using the log-rank test.

\section{Results}

Patient characteristics. The baseline characteristics of the 31 patients (19 men and 12 women) are summarized in Table I. Briefly, the median age at the first line of FOLFOX was 61.9 years (range, 27.9-78.2 years). The majority of the patients had digestive or lung neuroendocrine carcinoma: The primary site was the pancreas in 14 , the digestive tract in 3 and the lung in 8 patients, while the 6 remaining patients had primary tumors of unknown origin; 21 initially had a poor performance status $(\geq 2)$, and $28(90 \%)$ had tumor-related symptoms (abdominal pain and carcinoid syndrome). All the patients had well-differentiated metastatic carcinomas. The Ki-67 index was available for 30 of the 31 patients: in 3 cases, the Ki-67 was $<2 \%$ (G1), while 28 patients had a Ki-67 index of $2-20 \%$ (G2). ${ }^{18} \mathrm{~F}$-fluorodeoxyglucose positron emission tomography examination was performed in 27 patients and was positive in 26 . The median time from the diagnosis of metastasis to the initiation of the FOLFOX regimen was 28.72 months (range, 0-90 months). mFOLFOX was used as first-line therapy in 18 patients, second-line in 8 , and third- and fourth-line in 3 and 2 patients, respectively. The treatments previously received were as follows: Transcatheter arterial chemoembolization in 5 cases, PRRT in 1, targeted therapies 
Table I. Patient characteristics.

\begin{tabular}{|c|c|c|}
\hline Characteristics & $\mathrm{n}$ & $\%$ \\
\hline \multicolumn{3}{|l|}{ Gender } \\
\hline Male/female & $19 / 12$ & $61 / 39$ \\
\hline \multicolumn{3}{|c|}{ Site of primary tumor } \\
\hline Pancreas & 14 & 45 \\
\hline Lung & 8 & 26 \\
\hline Small intestine & 3 & 9.7 \\
\hline Unknown & 6 & 19.3 \\
\hline \multicolumn{3}{|c|}{ Initial performance status } \\
\hline 0 & 1 & 3 \\
\hline 1 & 9 & 30 \\
\hline 2 & 20 & 64 \\
\hline 3 & 1 & 3 \\
\hline \multicolumn{3}{|c|}{ No. of previous treatment lines } \\
\hline 0 & 18 & 58 \\
\hline 1 & 8 & 26 \\
\hline 2 & 3 & 10 \\
\hline 3 & 2 & 6 \\
\hline \multicolumn{3}{|c|}{ No. of metastatic sites } \\
\hline 0 & 0 & 0 \\
\hline 1 & 22 & 71 \\
\hline 2 & 9 & 29 \\
\hline \multicolumn{3}{|l|}{ Tumor syndrome } \\
\hline Yes & 28 & 90 \\
\hline No & 3 & 10 \\
\hline \multicolumn{3}{|l|}{ FDG PET } \\
\hline Positive/negative & $26 / 1$ & $84 / 3$ \\
\hline Not performed & 4 & 13 \\
\hline
\end{tabular}

FDG, fluorodeoxyglucose; PET, positron emission tomography.

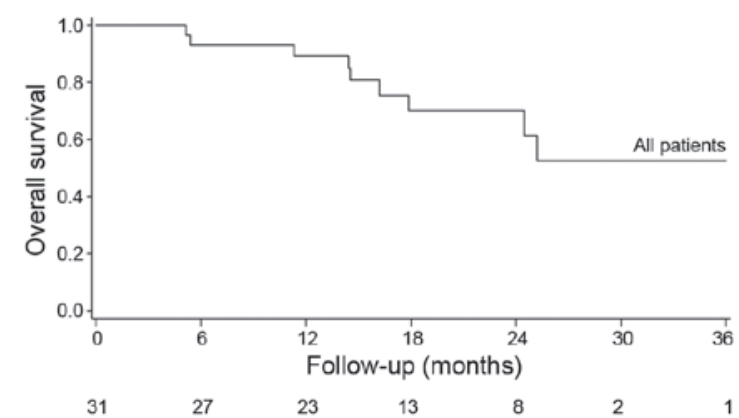

Figure 1. Overall survival of a population of 31 metastatic NETs treated by mFOLFOX chemotherapy.

in 5, and chemotherapy (dacarbazine, temozolomide, STZ, cisplatin + etoposide) in 13 cases.

The median follow-up was 20 months [95\% confidence interval (CI):15-27]. Based on CT or MRI evaluation, 9 patients $(29 \%)$ showed a partial response, and $13(41 \%)$ had stable disease. The disease control rate was 70\%; 9 patients exhibited disease progression. The control rate was $78 \%$ for pancreatic and $65 \%$ for extrapancreatic NETs.
The baseline CgA level was available (and initially high) in 15 patients. A total of 13 patients exhibited a decrease in the $\mathrm{CgA}$ level (in 9 cases the level decreased by $>50 \%$, including 3 cases exhibiting a decrease of $>80 \%$ ), whereas 2 patients exhibited an increase by 3 and $20 \%$, contradicting the radiological evidence of partial response and stable disease, both indicating clinical benefit.

Overall, 22 patients had a clinical benefit, whereas 9 did not experience any clinical improvement. Among the 22 patients who had a clinical benefit, 9 exhibited partial tumor response, 12 had stable disease, and 1 had progressive disease. Among the 9 patients without clinical improvement, 8 had progressive disease and 1 had stable disease. The clinical benefit was observed after 1 or 2 treatment cycles.

The median OS was not reached; the 1- and 2-year OS was 89 and $70 \%$, respectively (Fig. 1). No significant difference in OS was observed between the Ki-67 subgroups ( $<5$ and 5-20\%; $\mathrm{P}=0.41$ ) (Fig. 2A) or according to the primary tumor location ( $\mathrm{P}=0.71$; Fig. 2B). The median PFS was 14.1 months (95\% CI: 9.3-24.1), with no significant difference in PFS between the Ki-67 subgroups ( $\mathrm{P}=0.26$; Fig. 3A) or according to tumor location $(\mathrm{P}=0.995$; Fig. 3B). The median TTF was 14.72 months (95\% CI:10.0-non-estimable).

Overall, 235 cycles of mFOLFOX were administered, of which 158 (67\%) were administered at full dose. The median number of mFOLFOX cycles administered per patient was 6 (range, 1-22). No unusual toxicity or toxicity-related deaths were reported. No patients discontinued FOLFOX due to severe toxicity, while 3 patients discontinued FOLFOX early due to clinical proof of disease progression after 2 or 4 weeks of FOLFOX therapy. Oxaliplatin dose reduction of 10-30\%, usually due to mild neurotoxicity, was required in 17 patients.

Finally, 7 of the 9 patients who had partial response benefited from a break in treatment, lasting $\geq 3$ months. The median duration of this break was 9.2 months (range, 3-42 months). Of the 13 patients with stable disease, 12 also benefited from a chemotherapy break. The median duration of this break was 10 months (range, 0.5-26 months); 9 of the 13 patients with stable disease received somatostatin analogues. Following disease progression, 7 of these patients resumed the same FOLFOX treatment.

\section{Discussion}

Although no definitive conclusions may be drawn from our series of patients due to the retrospective nature of this study, the small number of patients and the heterogeneity of the underlying disease, certain observations were made. In our series, the overall disease control rate was $70 \%$, with a $29 \%$ objective response rate. The FOLFOX combination appears to be effective, even in this heavily pretreated population. The comparison with response rates obtained with previously published combinations is complex (25). However, our results appear to be better compared with the results obtained with interferon or with the combination of interferon with 5FU, with a $9 \%$ partial response rate, even in carcinoid tumors (26), and similar to the results obtained with a combination of 5FU, doxorubicin and STZ in pancreatic NETs (response rate of $39 \%$, median response duration of 9.3 months, 2-year PFS rate of $41 \%$ and 2-year OS rate of 74\%) (27), XELOX (30\% partial 

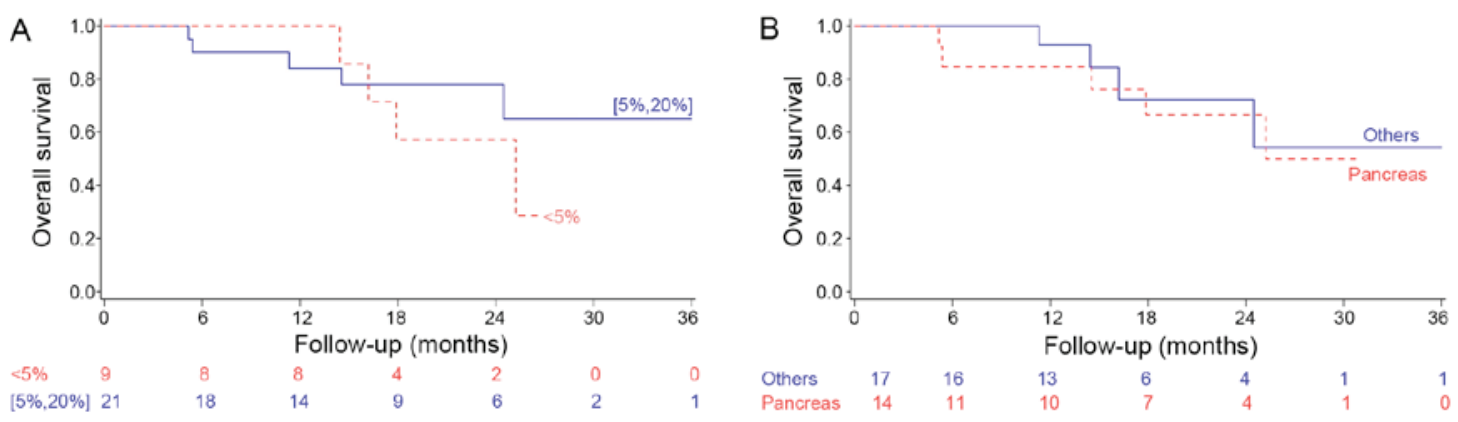

Figure 2. Overall survival by (A) Ki-67 immunolabeling (<5 vs. 5-20\%) and (B) primary location (pancreas vs. other locations).
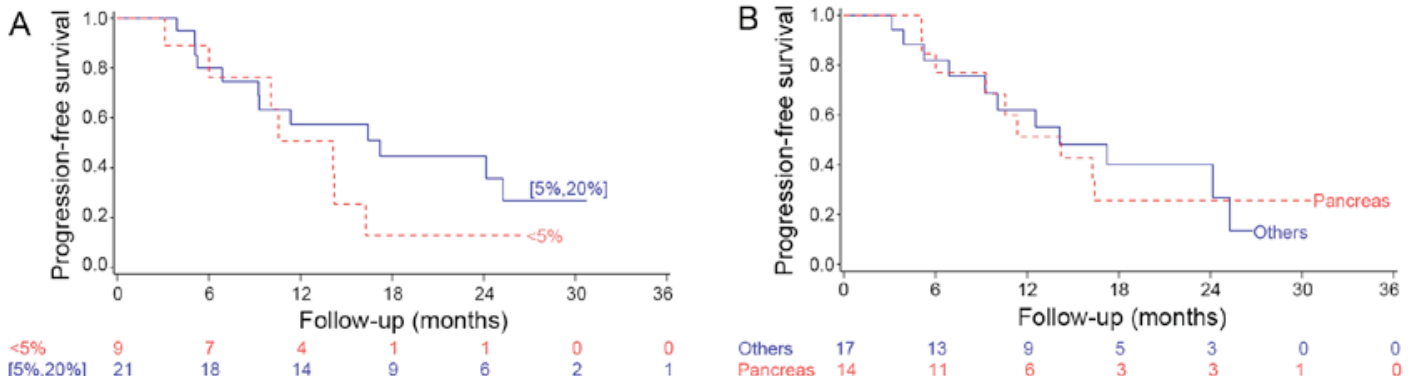

Figure 3. Progression-free survival by (A) Ki-67 immunolabeling ( $<5$ vs. $5-20 \%)$ and (B) primary location (pancreas vs. other locations).

response and $48 \%$ stable disease) (23), or GEMOX (28). The results obtained with temozolomide appeared better but largely depend on $\mathrm{O}^{6}$-methylguanine DNA methyltransferase expression $(29,30)$.

To the best of our knowledge, none of those studies had taken an active interest in the possibility of a prolonged break in chemotherapy. We observed the possibility of a prolonged break with improvement of the quality of life and symptoms, in both partial responders and patients with stable disease. In NETs, FOLFOX may be integrated into 'stop and go' strategies, as in colorectal cancer, with improvement of the quality of life, which is particularly important for a disease where the cumulative toxicity of chemotherapy is a major consideration. After a prolonged break in patients with partial response or stable disease, the same chemotherapy may be performed again with good results, as in our series.

The use of antiangiogenic drugs in NETs has been investigated in patients who are stable on octreotide. In a phase II study, bevacizumab achieved an objective response, radiological reduction in blood flow and longer PFS compared with interferon $\alpha$. The combination of chemotherapies with bevacizumab has also been investigated. The BETTER trials $(31,32)$ recently evaluated the combination of bevacizumab and capecitabine in gastrointestinal NETs and of bevacizumab combined with 5FU/STZ in progressive pancreatic NETs; both studies conducted in the first-line setting demonstrated clinical effectiveness and a manageable safety profile with a promising median PFS at 24 months.

The improvement of symptoms is of interest, even in cases of radiological stability. Improvement in clinical signs and biochemical activities that contradict minor antitumor activity on imaging has been described in NETs following treatment with somatostatin analogs (33) and interferon $\alpha$ (34).
In conclusion, our overall experience with FOLFOX chemotherapy indicates that this combination is feasible and exhibits promising activity in patients with either previously treated or untreated NETs. Improvement may be obtained through combination with antiangiogenic drugs (35-38). Chemotherapy breaks were possible in the majority of the cases, alleviating treatment-related toxicity and improving the quality of life of the patients.

\section{References}

1. Lepage C, Bouvier AM, Phelip JM, Hatem C, Vernet C and Faivre $\mathrm{J}$ : Incidence and management of malignant digestive endocrine tumours in a well defined French population. Gut 53: 549-553, 2004.

2. Modlin IM, Oberg K, Chung DC, Jensen RT, de Herder WW, Thakker RV, Caplin M, Delle Fave G, Kaltsas GA, Krenning EP, et al: Gastroenteropancreatic neuroendocrine tumours. Lancet Oncol 9: 61-72, 2008.

3. Vélayoudom-Céphise FL, Duvillard P, Foucan L, Hadoux J, Chougnet CN, Leboulleux S, Malka D, Guigay J, Goere D, Debaere T, et al: Are G3 ENETS neuroendocrine neoplasms heterogeneous? Endocr Relat Cancer 20: 649-657, 2013.

4. Zappa M, Abdel-Rehim M, Hentic O, Vullierme MP, Ruszniewski P and Vilgrain V: Liver-directed therapies in liver metastases from neuroendocrine tumors of the gastrointestinal tract. Target Oncol 7: 107-116, 2012.

5. Pavel M, Baudin E, Couvelard A, Krenning E, Öberg K, Steinmüller T, Anlauf M, Wiedenmann B and Salazar R; Barcelona Consensus Conference participants: ENETS Consensus Guidelines for the management of patients with liver and other distant metastases from neuroendocrine neoplasms of foregut, midgut, hindgut, and unknown primary. Neuroendocrinology 95: 157-176, 2012.

6. Maire F,Lombard-Bohas C, O'Toole D, Vullierme MP, Rebours V, Couvelard A, Pelletier AL, Zappa M, Pilleul F, Hentic O, et al: Hepatic arterial embolization versus chemoembolization in the treatment of liver metastases from well-differentiated midgut endocrine tumors: A prospective randomized study. Neuroendocrinology 96: 294-300, 2012. 
7. Rinke A, Müller HH, Schade-Brittinger C, Klose KJ, Barth P, Wied M, Mayer C, Aminossadati B, Pape UF, Bläker M, et al: Placebo-controlled, double-blind, prospective, randomized study on the effect of octreotide LAR in the control of tumor growth in patients with metastatic neuroendocrine midgut tumors: A report from the PROMID Study Group. J Clin Oncol 27: 4656-4663, 2009.

8. Caplin ME, Pavel M, Ćwikła JB, Phan AT, Raderer M, Sedláčková E, Cadiot G, Wolin EM, Capdevila J, Wall L, et al: Lanreotide in metastatic enteropancreatic neuroendocrine tumors. N Engl J Med 371: 224-233, 2014.

9. Pavel ME, Hainsworth JD, Baudin E, Peeters M, Hörsch D, Winkler RE, Klimovsky J, Lebwohl D, Jehl V, Wolin EM, et al Everolimus plus octreotide long-acting repeatable for the treatment of advanced neuroendocrine tumours associated with carcinoid syndrome (RADIANT-2): A randomised, placebo-controlled, phase 3 study. Lancet 378: 2005-2012, 2011.

10. Yao JC, Shah MH, Ito T, Bohas CL, Wolin EM, Van Cutsem E, Hobday TJ, Okusaka T, Capdevila J, de Vries EG, et al: Everolimus for advanced pancreatic neuroendocrine tumors. N Engl J Med 364: 514-523, 2011

11. Raymond E, Dahan L, Raoul JL, Bang YJ, Borbath I, Lombard-Bohas C, Valle J, Metrakos P, Smith D, Vinik A, et al: Sunitinib malate for the treatment of pancreatic neuroendocrine tumors. N Engl J Med 364: 501-513, 2011.

12. Waldherr C, Pless M, Maecke HR, Haldemann A and Mueller-Brand J: The clinical value of [90Y-DOTA]-D-Phe1-Ty r3-octreotide (90Y-DOTATOC) in the treatment of neuroendocrine tumours: A clinical phase II study. Ann Oncol 12: 941-945, 2001.

13. Imhof A, Brunner P, Marincek N, Briel M, Schindler C, Rasch H, Mäcke HR, Rochlitz C, Müller-Brand J and Walter MA: Response, survival, and long-term toxicity after therapy with the radiolabeled somatostatin analogue [90Y-DOTA]-TOC in metastasized neuroendocrine cancers. J Clin Oncol 29: 2416-2423, 2011

14. Öberg K, Knigge U, Kwekkeboom D and Perren A; ESMO Guidelines Working Group: Neuroendocrine gastro-entero-pancreatic tumors: ESMO Clinical Practice Guidelines for diagnosis, treatment and follow-up. Ann Oncol 23 (Suppl 7): vii124-vii130, 2012.

15. Moertel CG, Hanley JA and Johnson LA: Streptozocin alone compared with streptozocin plus fluorouracil in the treatment of advanced islet-cell carcinoma. N Engl J Med 303: 1189-1194, 1980

16. Sun W, Lipsitz S, Catalano P, Mailliard JA and Haller DG; Eastern Cooperative Oncology Group: Phase II/III study of doxorubicin with fluorouracil compared with streptozocin with fluorouracil or dacarbazine in the treatment of advanced carcinoid tumors: Eastern Cooperative Oncology Group Study E1281. J Clin Oncol 23: 4897-4904, 2005.

17. Crona J, Fanola I, Lindholm DP, Antonodimitrakis P, Öberg K, Eriksson B and Granberg D: Effect of temozolomide in patients with metastatic bronchial carcinoids. Neuroendocrinology 98: $151-155,2013$

18. de Gramont A, Figer A, Seymour M, Homerin M, Hmissi A Cassidy J, Boni C, Cortes-Funes H, Cervantes A, Freyer G, et al: Leucovorin and fluorouracil with or without oxaliplatin as first-line treatment in advanced colorectal cancer. J Clin Oncol 18: 2938-2947, 2000

19. Louvet C, Labianca R, Hammel P, Lledo G, Zampino MG, André T, Zaniboni A, Ducreux M, Aitini E, Taïeb J, et al: Gemcitabine in combination with oxaliplatin compared with gemcitabine alone in locally advanced or metastatic pancreatic cancer: Results of a GERCOR and GISCAD phase III trial. J Clin Oncol 23: 3509-3516, 2005.

20. Cunningham D, Starling N, Rao S, Iveson T, Nicolson M, Coxon F, Middleton G, Daniel F, Oates J and Norman AR Upper Gastrointestinal Clinical Studies Group of the National Cancer Research Institute of the United Kingdom: Capecitabine and oxaliplatin for advanced esophagogastric cancer. N Engl J Med 358: 36-46, 2008.

21. André $\mathrm{T}$, Tournigand $\mathrm{C}$, Rosmorduc $\mathrm{O}$, Provent $\mathrm{S}$, Maindrault-Goebel F, Avenin D, Selle F, Paye F, Hannoun L, Houry S, et al: Gemcitabine combined with oxaliplatin (GEMOX) in advanced biliary tract adenocarcinoma: A GERCOR study. Ann Oncol 15: 1339-1343, 2004.

22. Tetzlaff ED and Ajani JA: Oxaliplatin-based chemotherapy for the treatment of a metastatic carcinoid tumor. Int J Gastrointest Cancer 36: 55-58, 2005.

23. Bajetta E, Catena L, Procopio G, De Dosso S, Bichisao E, Ferrari L, Martinetti A, Platania M, Verzoni E, Formisano B and Bajetta R: Are capecitabine and oxaliplatin (XELOX) suitable treatments for progressing low-grade and high-grade neuroendocrine tumours? Cancer Chemother Pharmacol 59: 637-642, 2007.
24. Chibaudel B, Tournigand C, Bonnetain F, Maindrault-Goebel F Lledo G, André T, Larsen AK, Bengrine-Lefevre L, Louvet C and de Gramont A: Platinum-sensitivity in metastatic colorectal cancer: Towards a definition. Eur J Cancer 49: 3813-3820, 2013.

25. Moertel CG, Lefkopoulo M, Lipsitz S, Hahn RG and Klaassen D: Streptozocin-doxorubicin, streptozocin-fluorouracil or chlorozotocin in the treatment of advanced islet-cell carcinoma. N Engl J Med 326: 519-523, 1992.

26. Dahan L, Bonnetain F, Rougier P, Raoul JL, Gamelin E, Etienne PL, Cadiot G, Mitry E, Smith D, Cvitkovic F, et al: Phase III trial of chemotherapy using 5-fluorouracil and streptozotocin compared with interferon alpha for advanced carcinoid tumors: FNCLCC FFCD 9710. Endocr Relat Cancer 16: 1351-1361, 2009.

27. Kouvaraki MA, Ajani JA, Hoff P, Wolff R, Evans DB, Lozano R and Yao JC: Fluorouracil, doxorubicin, and streptozocin in the treatment of patients with locally advanced and metastatic pancreatic endocrine carcinomas. J Clin Oncol 22: 4762-4771, 2004.

28. Cassier PA, Walter T, Eymard B, Ardisson P, Perol M, Paillet C, Chayvialle JA, Scoazec JY, Hervieu V and Bohas CL: Gemcitabine and oxaliplatin combination chemotherapy for metastatic well-differentiated neuroendocrine carcinomas: A single-center experience. Cancer 115: 3392-3399, 2009.

29. Kulke MH, Hornick JL, Frauenhoffer C, Hooshmand S, Ryan DP, Enzinger PC, Meyerhardt JA, Clark JW, Stuart K, Fuchs CS and Redston MS: O6-methylguanine DNA methyltransferase deficiency and response to temozolomide-based therapy in patients with neuroendocrine tumors. Clin Cancer Res 15: 338-345, 2009.

30. Ekeblad S, Sundin A, Janson ET, Welin S, Granberg D, Kindmark H, Dunder K, Kozlovacki G, Orlefors H, Sigurd M, et al: Temozolomide as monotherapy is effective in treatment of advanced malignant neuroendocrine tumors. Clin Cancer Res 13: 2986-2991, 2007.

31. Ducreux M, Dahan L, Smith D, O'Toole D, Lepère C, Dromain C, Vilgrain V, Baudin E, Lombard-Bohas C, Scoazec JY, et al: Bevacizumab combined with 5-FU/streptozocin in patients with progressive metastatic well-differentiated pancreatic endocrine tumours (BETTER trial)-a phase II non-randomised trial. Eur J Cancer 50: 3098-3106, 2014.

32. Mitry E, Walter T, Baudin E, Kurtz JE, Ruszniewski P, Dominguez-Tinajero S, Bengrine-Lefevre L, Cadiot $\mathrm{G}$, Dromain C, Farace F, et al: Bevacizumab plus capecitabine in patients with progressive advanced well-differentiated neuroendocrine tumors of the gastro-intestinal (GI NETs) tract (BETTER trial)-a phase II non-randomised trial. Eur J Cancer 50: 3107-3115, 2014.

33. Rinke A, Müller H-H, Schade-Brittinger C, Klose KJ, Barth P, Wied M, Mayer C, Aminossadati B, Pape UF, Bläker M, et al: Placebo-controlled, double-blind, prospective, randomized study on the effect of octreotide LAR in the control of tumor growth in patients with metastatic neuroendocrine midgut tumors: A report from the PROMID Study Group. J Clin Oncol 27: 4656-4663, 2009.

34. Bajetta E, Zilembo N, Di Bartolomeo M, Di Leo A, Pilotti S, Bochicchio AM, Castellani R, Buzzoni R, Celio L, Dogliotti L, et al: Treatment of metastatic carcinoids and other neuroendocrine tumors with recombinant interferon-alpha-2a. A study by the Italian Trials in Medical Oncology Group. Cancer 72: 3099-3105, 1993.

35. Chu E: Bevacizumab targeted therapy: Validation of angiogenesis as a key target for advanced colorectal cancer. Clin Colorectal Cancer 4: 16, 2004.

36. Tabernero J, Van Cutsem E, Lakomý R, Prausová J, Ruff P, van Hazel GA, Moiseyenko VM, Ferry DR, McKendrick JJ, Soussan-Lazard K, et al: Aflibercept versus placebo in combination with fluorouracil, leucovorin and irinotecan in the treatment of previously treated metastatic colorectal cancer: Prespecified subgroup analyses from the VELOUR trial. Eur J Cancer 50: 320-331, 2014.

37. Yao JC, Phan A, Hoff PM, Chen HX, Charnsangavej C, Yeung SC, Hess K, Ng C, Abbruzzese JL and Ajani JA: Targeting vascular endothelial growth factor in advanced carcinoid tumor: A random assignment phase II study of depot octreotide with bevacizumab and pegylated interferon alpha-2b. J Clin Oncol 26: 1316-1323, 2008

38. Chan JA, Stuart K, Earle CC, Clark JW, Bhargava P, Miksad R, Blaszkowsky L, Enzinger PC, Meyerhardt JA, Zheng H, et al: Prospective study of bevacizumab plus temozolomide in patients with advanced neuroendocrine tumors. J Clin Oncol 30: 2963-2968, 2012 . 